\title{
Facing the technology challenge: Art education concepts and digital media in Germany
}

\section{Enfrentando o Desafio Tecnológico: conceitos de arte-educação e mídia digital na Alemanha}

\section{Daniela Reimann}

\section{Simone Bekk}

\begin{abstract}
Though cutting edge media technologies have been introduced into art education at school in general education in 2001 (REIMANN et al., 2003), there is still big scepticism about integrating the computer and digital media into the art lessons at school. Some perceive it time consuming, taking away urgently needed time for drawing and painting, others do not agree with the idea of addressing technology issues such as programming and coding as a form of media literacy in the art classroom. The research project MediaArt@Edu (Acronym) which is funded by the German Federal Ministry of Education and realised in collaboration with ZKM, the Centre for Media and Art Karlsruhe, as well as the Agency for Employment Karlsruhe, will be presented. It links artistic approaches to interactive technology in creative processes with disadvantaged, and unemployed young people in vocational preparation measures.

Keyword: Media. Art. Technology. Education. Portfolio.
\end{abstract}

Resumo: Embora tecnologias de mídia de ponta tenham sido introduzidos no ensino da arte na escola do ensino geral em 2001 (REIMANN et al., 2003), ainda há grande ceticismo sobre a integração do computador e mídia digital para as aulas de arte na escola. Alguns areditam que toma tempo tirando o tão necessário tempo para desenho e pintura, outros não concordam com a idéia de abordar as questões de tecnologia tais como programação e codificação como uma forma de alfabetização mediática na sala de aula de arte. O projeto de pesquisa MediaArt@Edu (sigla), que é financiado pelo Ministério Federal Alemão de Educação e realizado em colaboração com o ZKM, o Centro de Mídia e Arte Karlsruhe, bem como a Agência para o Emprego Karlsruhe, será discutido. Este liga abordagens artísticas a tecnologia interativa em processos criativos com jovens desfavorecidos e desempregados como medidas integradoras de preparação profissional.

Palavras-chave: Mídia. Arte. Tecnologia. Educação. Portfólio.

\section{Introduction to the history of media art in Germany}

n Germany the relationship between technology and art grew in the 60s in the context of computer science and information aesthetics which developed from the early computer graphic and fraction art (represented by computer scientists and artists like Nake, and Nees) and video art (Paik) towards the contemporary interactive media art. The development of such art work which 
constituted a new genre was supported and hosted in institutions like the Zentrum für Kunst und Medientechnologie Karlsruhe (ZKM). Rather than a traditional museum, ZKM can be seen as centre international of art and media, including research departments as well as artist in residence programs.

Nowadays, the media art concept incorporates a variety of lines and, consequently, should not be discussed in general terms. What these concepts have in common is the artist's attitude in handling analogue and digital media which often is characterized by a critical, reflecting attitude towards the medium and is established against the usual applications and the mainstream. It developed from the computer art of the sixties to analogue video art to interactive media art of the nineties. Following the philosopher, Max Bense (1910-90) and his studies of science theory, logic, aesthetics (Aesthetica, 1965), and semiotics (1967), the aesthetics of information developed with representatives such as Frieder Nake and Georg Nees. Nake covered aesthetics as information processing (1974) on the basis of computer science. He described the algorithmic image as one representative of classes of digital images (REIMANN, 2005).

In the 1980/90s, against the background of flickering, noisy video images and growing floods of pictures, analogue media art developed in particular in connection with the video medium. Nam June Paik in the seventies, like no other author, tried the artistic potential of TV and videos from the Fluxus movement and the happenings of the sixties.

The spread of the World Wide Web and the introduction of multimedia computers in households increasingly caused artists in the nineties to employ the digital medium as a subject, for tests, and for use. Intermedia strategies combining analogue, digital media and a variety of design practices determined media art in the nineties, such as the work by Alba D'Urbano. At the same time, female artists developed strategies of Net art exploring the Internet less as a tool for publication and research but rather as a medium of art (e.g. the artist group Jodi), or reflecting on it within the framework of hypermedia and storytelling, and formulating web criticism (Heiko Idensen) or political activism (e.g. like the Austrian Net artists and activists Übermorgen.com perceived and presented not only in the German media art scene). Between the late nineties and today, artists also have worked on the language of the digital medium, the code and the computer science model, respectively. Some artists and groups of artists also looked into the subject of programming (e.g. Christa Sommerer and Laurent Mignonneau and others). They represent exceptions acquiring programming as a digital tool to shape and manipulate the machine, using it for artistic purposes, and exploring the opportunities opening up as well as functionalities. For a long time, division of labour, i.e. the separation of an artistic concept and more technical issues such as programming as well as the implementation of interactive pieces of work, was the rule and is still widespread in the media art scene.

Within the framework of Virtual Reality, Augmented and Mixed Reality, expanded interfaces in media art were developed in interdisciplinary projects. Jeffrey Shaw created Legible City (1988-91), a virtual city made up of letters the user explores by operating the pedals of a vehicle and, in this way, navigating in digital space. This indeed is a classic of interactive media art, which nowadays shows the huge step in terms of the development of computer graphics - from the a pixel by pixel aesthetic of the late $80 \mathrm{~s}$ and $90 \mathrm{~s}$, towards the high resolution of today's games and virtual worlds delivered through the Net.

Monika Fleischmann and Wolfgang Strauss took up the Mixed Reality concept from computer science, linking it to artistic contexts in their work. Their concepts are located in the dichotomy of 
art and science. Among other things, they work on artistic concepts of interfaces and awareness systems. The awareness concept arose in connection with telepresence, virtual reality (VR), and omnipresent observing systems:

Awareness methods linking media space and real space are suitable for navigation purposes measure and indicate the change from one digital state into another, e.g., computer vision or tracking systems, web cameras, electronic fields, sensors, etc. These changes can be seen, heard, felt, i.e. experienced. [...] Early awareness concepts can be found [...] in telematic art projects, from 'Hole in Space' to 'Telematic Dreaming' by Paul Sermon up to Steve Martin and his personal surveillance system, one of the first projects of Wearable Computing. (FLEISCHMANN; STRAUSS, 2001 apud REIMANN, 2006, p. 106)

When the Centre of Art and Media Technology (ZKM) was founded in 1989 in Karlsruhe, in the German Land of Baden-Württemberg, interactive media art was given a new place of its own in the early nineties. The basic idea is described by its founder, Heinrich Klotz as follows:

The task envisaged for the ZKM is the sounding out of the creative possibilities between the traditional arts and media technologies for the purpose of achieving innovative results. The objective is the enrichment of the arts, not their technical amputation. For this reason both traditional and media arts must compete with one another. At the ZKM either aspect - each for itself and with one another - are given a voice. The Bauhaus, founded in Weimar in 1919, may serve as a model. (KLOTZ cited on BEHR 2009)

Extended interface concepts, such as acoustic and tangible interfaces, and tracking systems more and more were reflected and displayed in works of art. The classics of media art are kept at the ZKM Media Museum. The interactive medium existing as a concept as early as in analogue media art (by integrating observers more closely into the concept of a work of art) increasingly was scrutinized and explored in a playful way in digital media art. Work with interactive media enabled artists to cooperate with engineers, technicians and computer scientists in an interdisciplinary fashion, though mainly by division of labour. Only in the nineties, programming tools began to be explored by artists, and it was reflected in a variety of processes, among them those of Sommerer and Mignonneau, the Jodi group of artists, and Cornelia Sollfrank (Hacking Art). These artists acquired skills in programming or designed their own software tools.

Artistic exploration of the programmable medium also requires interactivity to be made a subject. One question arising to artists was that of the value to media and the aesthetics of a digital medium. The interactive medium, i.e. a medium showing behaviour, incorporates the digital image. The traditional image concept is expanded - from a static to a dynamic object up to an interactive image space. The digital image as an algorithmic image, i.e. an image behaving dynamically, raises new questions in the visual arts and in the science of art, especially with regard to the concepts of image and education which increasingly has spread to the ambient interactive dynamic image space. The actual carrier of a digital image is the algorithm located behind the screen surface. It contains the characteristics of the digital medium. Only the representative of an algorithmic image 
becomes visible on the surface of the computer. Consequently, the digital image exists in two ways: as a computed model which can be manipulated, and as a representative (icon) of pixels in a bit pattern behind and on the surface. Visual arts are enriched by the algorithmic character of the digital image adding the dimension of behaviour, that is, such media are interactive rather than static, and interactivity is their main characteristic. However such concept was not only addressed as a learning content and educational goal to aspire to in traditional German art education, but in the model project on Integrated Art and Computer Science in Education at School and University (Acronym: ArtDeCom) (REIMANN, 2006).

In the World of Games. Reloaded exhibition, the ZKM in 2004/05 also displayed current commercial computer games within the Algorithmic Revolution show. The exhibition has been updated and renamed ZKM_Gameplay.

ZKM_Gameplay is the new permanent exhibition on the theme of video games and experimented forms of play. Since its opening in 1997, numerous computer games have been presented at the ZKM | Media Museum in Karlsruhe, since these reflect an essential part within modern society heavily influenced by digitalized realities of life. For centuries new artistic, experimental, media-reflective as well as 'serious' games have evolved. The cultural and economic power of digital games and gameplay have experienced and continuous growth. This has made the games an important object of the ZKM. (ZKM, 2014, s/p.)

The history of development of games was presented in the ancestral gallery by Frank den Ousten/ Friedemann Schindler by the classic examples of Atari, Amigo, Odissey 2001 (Pong), Gameboy (Tetriss), Commodore, and Nintendo. Besides the familiar Playstation-2 applications, also the Dark Wind (Gametrack video) study was displayed where visitors, by operating the gloves of a tracking system, start fighting a character in the game by making real physical movements. What is interesting in this respect above all is the extended interface achieved by the haptic input system by tracking, which makes the game a veritable mixed-reality game system.

Also computer games established a new genre of art. The slot machines familiar from the gaming halls of the seventies can be considered historic precursors of later video games and game consoles for home use. With the increasing spread of personal computers, the two technically different types of video games developed, i.e. game consoles and computer games. In the mid-eighties, computer games, such as Nintendo and Gameboy, entered nurseries (REIMANN, 2005).

Computer games also helped the game segment to develop into a new, independent form of art. Applying specific strategies and concepts, artists responded to the products of the mass market of multimedia game worlds, their technical and aesthetic standards, and reflected them from scratch.

Interdisciplinary media art constitutes a special didactic potential for aesthetic-artistic media education which can be used in learning processes and design processes as an interdisciplinary, project-oriented tool. Interactive media art establishes links among disciplines, spaces, and bodies 
kept and reflected in aesthetic-artistic media projects (REIMANN, 2006).

\section{The media art education approach of the research project MediaArt@Edu}

The number of participants who leave school without any certificate or bad grades, so that they cannot access training in the context of an official apprenticeship is increasing in Germany and other European countries. Because of the compulsory school attendance in Germany, those pupils are transferred to so called vocational preparation measures either inside or outside vocational schools. The latter are organized by the German federal Agency of Employment administered in the city branches in the different German Länder. The young participants are obliged to take part in one year measures offered by the agency and its sub contracted training providers. In the courses offered, young people are supposed to get prepared for the labour market, in order for them to be enabled to take up a formal vocational training place (apprenticeship) or job in the future. Often those young people are placed in a long term transit situation, since the vocational preparation measure do not lead to any training qualification. The number and variety of measures offered is as wide as confusing, not only to the participants who are overwhelmed with information and offers they can hardly select. However, in the project proposal we argued, that those youngsters do not need another information overload about new measures, rather than positive learning and working experiences. We want to put them into an active position to develop their own interest in work in team projects to experience media technologies in a different way, that is, rather than consuming media, we enable them to shape and design project ideas, linked to 5 modules such as robotics (REIMANN et. al. 2014), light installation (REIMANN; BEKK, 2014), games (REIMANN; BEKK, 2015), sound as well as smart textile (REIMANN, 2011). In the paper, the module GamesLab ON/OFF will be presented, including examples of games design projects bringing together digital media and performative activities in physical space. We consider game design as reasonable and rich resource bringing together different sorts of activities and competences required, such as play and playful experimenting with different media and material. As Jenkins highlighted play can be defined as "the capacity to experiment with one's surroundings as a form of problem-solving" (JENKINS et al., 2009, p. 4). The online / offline approach also opens up the opportunity to link screen based activities to performative action and body movements. Also game design allows for the participants to design their own media products rather than simply consuming existing applications available on the market. 
Figura 1 - Activities and learning contents practiced in the GamesLab ON/OFF

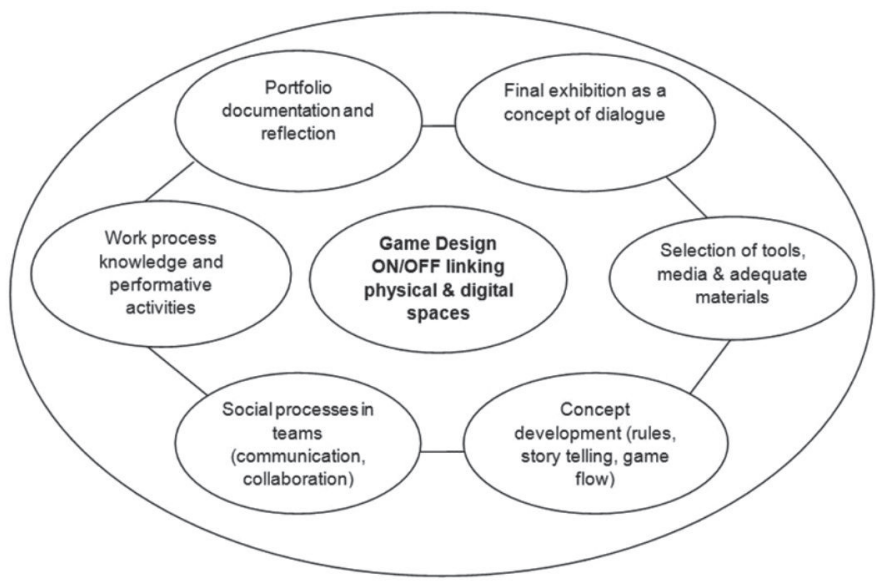

Source: Reimann; Bekk (2015).

The project's aim is to develop and realize media art workshops settings for young people based on art education processes with digital media, taught by referees of the ZKM's department of museum communications. Those project based arrangements are mentored by KIT students of general, vocational and engineering education as well as students of technical subjects such as electronic engineering, computer science, machine engineering and architecture who aim to archive so called key qualifications in the frame work of the university seminar linked to the project. Apart from attending the 3 day fulltime workshops and developing media objects, the young people are asked to document and reflect their project in the context of a project portfolio. It consists of the project development and documenting the working and design processes as well an online reflection part including feedback to the mentors, and a so called explanation video in which the finalized project is presented by the developers themselves to an external audience (e.g. future employers), and projected in the final exhibition. Apart from that, a blog is developed for sustainable access to the project for the participants.

\section{Research methodology, design and instruments}

MediaArt@Edu is both a research and development project, which intends to develop a concept of mentoring as well as a portfolio. The qualitative methodology consists of several parts. Besides the development of project portfolios, and art education methods linked to the very topic of each module, the research questions refer to the following areas of research:

- Portfolio design: The formative development (in progress along the project duration) of the MediaArt@Edu portfolio in response to the requirements along the topical media modules und its application/test in vocational preparation. It aims to focus on visualization of processes 
in order to make the activities and skills applied transparent to the special target group of participants.

- Portfolio practice, which scrutinizes the application of the portfolio and the use by the participants

- The mentoring of the portfolio practice by the university students (outcome is a compendium/guide line of good mentoring of portfolio practice).

The evaluation of activities and skills practiced along the design processes is undertaken by the student mentors, according to an observation survey developed along the design and team work processes. Those are being observed by the accompanying student mentors who examine the processes and take minutes on the basis of the observation survey. Furthermore, the workshops are observed and recorded on video by the accompanying researchers and students. The 3 day fulltime workshops are followed by a joint reflection workshop as well as a feedback session with the students to collect feedback of the participants as well as of the students concerning the following research questions: How was the overall workshop perceived by participants and students? How did they perceive the open task and create work? What did they learn by designing the games (apart from handling the technology), in terms of core skills and key qualifications which are requested for any job profile? We further want to find out how was the portfolio practice perceived and what they thought was the purpose of developing the portfolio. Also we asked for possible opportunities to apply such skills and experiences in their vocational future.

The students were asked how they perceived the mentoring of the portfolio practice. Further the issue of learning in project contexts is addressed in the project. The examination of the original portfolios was undertaken by the mentors. Furthermore, feedback session and qualitative semi-structured group interviews with the social actors were realized in the project. Also videos of the workshop lessons, of the final exhibition were recorded.

\section{GamesLab ON/OFF a workshop setting for game design with portfolios}

At the beginning of the workshop the given tools, such as Makey Makey (MIT), an Arduino-based technology to turn everyday objects into computer keys and use the tangible physical objects of the environment as a computer key board, the art project Dead drop, a shared offline data store in public space to engage people in participating in it, as well as the software iMovie which comes along with the iPad, were introduced to the participants and their student mentors. This introduction aimed at developing an understanding of the technology and its potentials and was very important because of the open task given from the media pedagogue. The tools were not only introduced theoretically and discussed with respect to games and game development, but also tested in practise with given tasks from the instructor. In addition, single-lens cameras were used for photography, encoded zip files were generated, QR codes generated with a QR code generator to link to their recorded videos. It was also possible for the participants to bring in their own skills for example programming computer based games or cutting video-sequences. This was possible because the task to design in working groups a game at the interface of online and offline was a very open task. 
The open task also allowed the single groups different approaches for the concept development. It was possible to start with the technical aspect by choosing the technical feasible options and deciding which medium was used, as well as with the contents-related aspects by developing the background story first. This free working opportunity was highly appreciated by the workshop participants. One participant commented in an interview: We were free and we could decide what to do, which is much more fun. Otherwise, we would have been caught in a type of labyrinth. And another participant added: Free work allows to be more creative and to contribute own skills.

For designing a game the workshop participants formed groups with up to three participants in the vocational preparation. In the planning and development phase the groups were accompanied by a student mentor. The latter was not a full team member like the participants but had to support and advise the participants if they had problems with the open task, the planning of the work and the work scheduling. In this phase the participants had to interact, social skills, such as working in a team, solving conflicts and technical problems, establishing contacts, cooperating and making compromises e.g. were required in particular. Not only team working was required also individual work. The workshop focused on multidisciplinary aspects, such as the perception and defence of own interests, the ability to work under pressure, own responsibility, and the ability to reach decisions.

In the following table the game design and learning contents are summarized:

Figura 2 - Game design activities and learning contents.

\begin{tabular}{|l|l|}
\hline Activities of the pupils & Learning contents \\
\hline Working methods & - Work planning \\
(single person working, & - Self-dependent \\
team based working) & - Commitment \\
- Accuracy & - Concentration and endurance \\
- Social role in the team & - Team communication and agreements \\
- Collaborative problem solving \\
- Collaboration
\end{tabular}




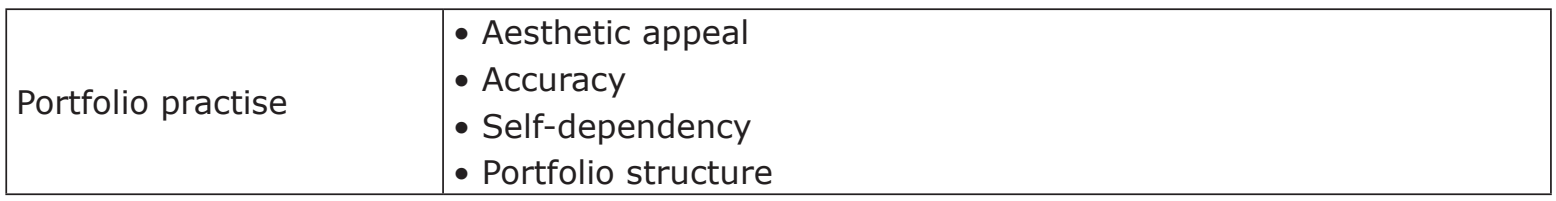

Source: Reimann; Bekk (2015).

The participants had to design a portfolio in the workshop. Portfolios usually are considered, and used as, collections of originals, such as sketches, drawings, and other documents, or as combinations of methods, processes or options for action. Aims and objectives of portfolios are selfmanagement, documentation, reflection as activation of the learner(s) (HÄCKER, 2007, SCHWARZ et al., 2008, REIMANN; Biazus, 2007). The specific MediaArt@Edu-portfolio design goes beyond the tool paradigm. It serves as an instrument to facilitate processes of self-directed learning, such as creative imagination, visualization, and reflection skills. The MediaArt@Edu project portfolio refers to earlier research undertaken at universities within the context of the Aesthetic Research Book (REIMANN; WÜST; BURKHART, 2014) portfolio variants and game design (REIMANN; BLOHM, 2006).

The MediaArt@Edu-portfolio consists of several parts. Firstly a poster, designed during the whole workshop, which shows the structure of the game. The poster also was presented at the exhibition. Secondly an online-questionnaire and feedback session with the student mentor was realized. Thirdly an explanation video, presenting the final project and the development and design processes, and also a blog were developed and realized by the participants. The underlying didactic approach was to visualize and to document the process and to enable the young people to explain their actions and working steps and to reflect them by communicating them to others in a reproducible manner. Another aim of the portfolio was to support the reflection about one's own acting, designing and thinking. As regards such an action- or design-oriented reflection of their own workflows and working steps, the participants were still untrained in reflecting their own workflow and working steps. The mentor had to support the participants.

Another (pragmatically) profit of the portfolio is, that the videos are deemed pieces of work, in which the participant is represented very concretely as a designing person and personality and it is shown that the participant is able to fulfil tasks and explain them. This video can be presented to future employers and on the basis of which job interviews may be conducted.

In the end, the workshop was evaluated, with the students and the participants rating the workshop in general, creative work, work on the portfolio poster, and in particular the artistic approach to covering a technical topic. The students additionally and separately assessed their work as mentors and their type of role.

A major element was the exhibition of the games at ZKM, as a didactic concept of dialogue. It was organized for friends, relatives of the participants and students as well as for all cooperation partners of the project. The participants had the chance to present their game design work in a museum context. For this the portfolio posters were exposed as well as the game installation and the explanation videos. Because of the presentation of the games by the young people themselves, the visitors were given the opportunity to discuss the designed work with the designer directly. To this effect the participants were confronted with new ideas, associations and contents concerning 
their games. An exchange of opinion was initiated between makers and visitors. This opportunity to present their games in a museum led to appreciation and relevance of the self-designed objects and enhanced the self-confidence of the young people in their own skills.

\section{Lessons learned}

In the following we summarize our first findings concerning the creative art education approach, the haptic dimensions of tangible media concept, the game design process as well as the portfolio method.

The creative art education approach with its open task and the free creative and experimental work to develop project ideas was perceived positively by the participants. This method is opposite to the common practice of school education where most tasks are less open for developing something according to one's own imagination, as participants pointed out in the interviews. Especially the haptic and tangible dimension of game development connecting physical space and virtual space of the computer (e.g. through the Makey Makey technology as well as the integration of the physical body of the player and its movements) was stressed to be an issue of relevance in the reflection survey by the participants. (Because in a group of three people and a mentor we developed and created something with our own hands and that's what I experienced positively. It was fun even though it was very exhausted. Participant, female, 19)

Through the game design processes they got into the position of being a game designer rather than a consumer. They were able to look behind the scenes and therefor developed and understanding of work processes, time frames and planning and testing. In this context they dealt in a different and experimental way with every day media experience and developed a creative product. The latter was presented in the final exhibition, which opened up the opportunity to present their games to an audience and get into dialogue about the projects.

As we found, portfolios can serve as useful instruments to support reflection of the participants' activities. However, portfolio work is not a common practice experienced at public school and needs to be introduced as a long term learning culture.

Summing it up we can conclude that the instruments chosen like portfolio, the soft- and hardware tools as well as the project based creative art education approach facilitated the participants perception and awareness concerning their own abilities, self-confidence and motivation. The project offers opportunities for the young people to experience learning in a positive and creative way. 


\section{References}

BEHR; K.G. Licht der Aufklärung, Zukunft der Künste. In: Die Rheinpfalz. 08.01.2009.

HÄCKER, T. Portfolio: ein Entwicklungsinstrument für selbstbestimmtes Lernen: Eine explorative Studie zur Arbeit mit Portfolios in der Sekundarstufe I. Baltmannsweiler. [S.I.]: Schneider Hohengehren, 2007. (Schul-und Unterrichtsforschung, 3)

JENKINS, $\mathrm{H}$. et al. Confronting the challenges of participatory culture: Media education for the 21st Century. Cambridge: The MIT Press, 2009. Available in: <https://mitpress.mit.edu/sites/default/ files/titles/free_download/9780262513623_Confronting_the_Challenges.pdf: Accessed: 23 July 2014.

REIMANN, D. Ästhetisch-informatische Medienbildung mit Kindern und Jugendlichen: Grundlagen, Szenarien und Empfehlungen für Gestaltungsprozesse in Mixed Reality-Lernräumen. Oberhausen: Athena, 2006.

REIMANN, D. Shaping Interactive Media with the Sewing Machine: Smart Textile as an Artistic Context to Engage Girls in Technology and Engineering Education. In: International Journal of Art, Culture and Design Technologies, v. 1, no. 1, p 12-21, 2011.

REIMANN, D.; BEKK, S. Game design with portfolios and creative skills, in: Zagalo, Nelson/Branco, Pedro (eds. 2015): Creativity in the Digital Age, Springer, p. 245-261

REIMANN, D.; BEKK, S. Künstlerisch geleitete Medienbildung mit Portfolios: Potenziale für Jugendliche in berufsvorbereitenden Bildungsmaßnahmen. Herausforderungen beim Übergang Schule - Beruf und das Konzept der berufsbiografischen Gestaltungskompetenz. Medienimpulse, n. 2, 2014. Available in: <http://medienimpulse.at/articles/view/659>. Accessed: 23 May 2016

REIMANN, D.; BIAZUS, M.C. Augmented virtual 3D-Community spaces as an intercultural interface for higher media art education. In: KOSCHKE, R.; OTTHEIN, H.; RÖDIGER, K.-H.; RONTHALER, M. (Hrsg.) Informatik 2007, Informatik trifft Logistik. Bremen: [s.n.], 2007. Bd. 1, p. 528-534.

REIMANN, D.; WÜST, A.; BURKHART, Miriam. Digitale Medien als ästhetische Erfahrungsräume für Jugendliche in berufsvorbereitenden Bildungsmaßnahmen. In: KAMMERL, R.; UNGER, A.; GRELL, P.; HUG, T. (Hrsg.). DGfE: Diskursive und produktive Praktiken in der Digitalen Kultur. [S.I; s.n.], 2014.

REIMANN, D.; WINKLER, T.; HERCZEG, M.; HÖPEL, I.: Exploring the Computer as a Shapeable Medium by Designing Artefacts for Mixed Reality Environments in Interdisciplinary Education Processes, in: Proceedings of the ED-MEDIA, World Conference on Educational Multimedia, Hypermedia and Telecommunications 2003, Honolulu, Hawaii 2003, p. 915-923 
SCHWARZ, J. et al. (Hrsg.). Portfolio im Unterricht. 13 Unterrichtseinheiten mit Portfolio. Seelze-Velber, 2008.

ZKM. ZKM_Gameplay. In: Kaepsele Connection. Karlsruhe: ZKM, 2014. Available in: <http://on1. zkm.de/zkm/stories/storyReader\$8340> Accessed:23 May 2016

\section{Acknowledgements}

The paper is based on the research project MediaArt@Edu - funded by the under the for Research planning and Education. Further we would like to thank the (GMK), an incorporate society concerned with media education and communication culture to support the idea of MediaArtLab@School. We would like to thank the BMBF, Federal Ministry of Education and Research and the DLR as well as the project partners Agentur für Arbeit Karlsruhe (agency for employment Karlsruhe) and their collaboration partners USS and AAW. We further thank the participants of the vocational preparation measures (BVB) of the year 2013/14 of the Agency of Employment Karlsruhe, department BVB as well as the referee Thorsten Belzer of the department Museum Communications (Head: Janine Burger) and Banu Beyer at ZKM, the Centre for Art and Media Karlsruhe. Further we thank the students of KIT, the members of the project team, namely Sabine Bauer, Raphaela Pelliccia, Nicole Widmann, Christian Schneider, Carolin Uller, as well as Tobias Brauchler who worked as student assistants and mentors in the module GameLab ON/OFF and who supported the evaluation of the project. 